\title{
RELAÇOES ENTRE COMPORTAMENTO DO FOGO E DANOS CAUSADOS A UM POVOAMENTO DE Pinus taeda *
}

\author{
DANIEL. SIMIONATO TOZZINI \\ Aerodata - Engenharia e Aerolevantamentos \\ RONALDO VIANA SOARES \\ Curso de Engenharia Florestal - UFPR
}

\section{SUMMARY}

This study intends to evaluate the damages caused to a Pinus taeda stand by forest fires ocurred on September 9, 10 an 11, 1981. The stand was located in Palmeira county, State of Paraná, Brazil, and the ages of the trees ranged from 8 to 10 years. Four levels of fire iritensity were visually defined: 1) Surface burning, without lethal crown scorch; II) Surface burning, with partial lethal crown scorch; III) Partial consumption of the crowns by the flames, and IV) Total consumption of the crowns by the flames. The estimated fire behavior parameters were flame height, Byram's fire intensity, and lethal scorch height. The average fire intensities were $44.3 \mathrm{kcal} /$ $\mathrm{m}$-s for level I; $293.0 \mathrm{kcal} / \mathrm{m}$-s for level II; $1,680.6$ $\mathrm{kcal} / \mathrm{m}-\mathrm{s}$ for leve! $11 \mathrm{l}$; and $12,345.6 \mathrm{kcal} / \mathrm{m}-\mathrm{s}$ for level IV. Average lethal scorch height were 1.4 and $9.7 \mathrm{~m}$ for levels $I$ and II respectively, surpassing the trees height for levels III and IV. In the areas where fire intensity reached levels III and IV all the trees were killed by the fire. On level II damage was partial and the trees recovered well. On level I fire intensity was too low to cause any kind of damage to the trees.

\section{INTRODUÇÃo}

As perdas de madeira causadas pelo fogo têm sido registradas de maneira generalizada em todo o mundo. No Brasil, apesar da carência de dados estatísticos, sabe-se que os incêndios florestais queimam milhares de hectares de florestas todos os anos, com enormes prejuizos tanto para o setor privado como para o público.

No caso dos incêndios florestais, saber apenas que eles ocorrem não é suficiente. Para se estabelecer uma política eficiente de prevenção e combate a esses incêndios é necessário saber onde, quando, porquê e quanto eles queimam. Para se conhecer os três primeiros aspectos, isto é, localização, época de maior ocorrência e principais causas, basta iniciar e manter um trabalho de coleta, arquivo e tabulação dos dados. A última parte porém, a quantificação dos danos, é mais técnica e exige a aplicação de uma metodologia adequada às condições brasileiras.

O objetivo deste trabalho é testar uma metodologia para quantificar e avaliar os danos produzidos por incêndios florestais em povoamento de Pinus taeda, utilizando alguns parâmetros do comportamento do fogo.

\section{REVISÃO DA LITERATURA}

Segundo NOSTE \& DAVIS ${ }^{5}$, a avaliação dos danos causados pelo fogo é um trabalho muito complexo. McARTHUR ${ }^{4}$ por sua vez diz que os danos causados à floresta pelos incêndios dependem da espécie atingida e da intensidade do fogo. Para uma intensidade baixa, semelhante a uma queima controlada, o fogo não afeta significativamente a floresta. Quando a intensidade é moderada pode ocorrer ataque de fungos e insetos devido à redução da resistência das árvores. Intensidades altas, quando não resultam na morte das árvores, causam severos danos à mesmas, reduzindo significativamente $o$ incremento e conseqüentemente $o$ volume final de madeira da floresta.

A fim de testar os efeitos dos incêndios sobre um povoamento de Pinus ponderosa no Arizona, DIETERICH ${ }^{2}$ usou uma intensidade média de fogo de $739 \mathrm{kcal} / \mathrm{m}$-s e observou que $24 \%$ das árvores morreram logo após o incêndio, $8 \%$ morreram de um a dois anos depois e $4 \%$ dois a três anos após o fogo, o que resultou numa mortalidade total de $48 \%$ das árvores ao final do período de observação. $\mathrm{O}$ autor observou ainda que as árvores

* Trabalho apresentado no $5^{\circ}$. Congresso Florestal Brasileiro, realizado em Recife, de 23 a 28 de novembro de 1986. 
cujo crestamento letal da copa não ultrapassou $90 \%$ da mesma sobreviveram.

VAN WAGNER ${ }^{9}$ estudando a influência da intensidade do fogo e da altura de crestamento letal das copas de coníferas adultas no Canadá, verificou que intensidades relativamente baixas não causam danos às árvores. Intensidades menores do que $100 \mathrm{kcal} / \mathrm{m}$-s e altura de crestamento letal de $8,0 \mathrm{~m}$ praticamente não afetaram as árvo. res; intensidades médias acima de $200 \mathrm{kcal} / \mathrm{m}$-s e altura de crestamento letal de $13 \mathrm{~m}$ causaram pequenos danos; entretanto, intensidades médias de $1.000 \mathrm{kcal} / \mathrm{m}$-s e altura de crestamento letal de $40 \mathrm{~m}$ causaram severos danos às árvores.

HERMAN $^{3}$ analisando os danos provocados pelo fogo em Pinus ponderosa, no sudoeste dos EUA, afirma que árvores com $60 \%$ ou mais de crestamento letal de copa apresentam baixo potencial de sobrevivência, cerca de $3 \%$, enquanto que $86 \%$ das árvores suportam alturas de crestamento letal inferiores a $60 \%$ da copa.

SOARES $^{8}$, em trabalho com queima controlada em plantios de Pinus caribaea hondurensis e $P$. oocarpa com 7 anos de idade, no triângulo mineiro, verificou que não houve mortalidade de árvores em nenhuma das duas espécies, quando submetidas a intensidades médias de fogo de 121,0 e $128,5 \mathrm{kcal} / \mathrm{m}-\mathrm{s}$, respectivamente.

\section{MATERIAL E MÉTODOS}

\subsection{Características da área}

A pesquisa foi desenvolvida na $F$ azenda $R$ io do Salto, de propriedade da Slaviero Florestal, localizada no município de Palmeira, Estado do Paraná. A área está situada entre os paralelos $25^{\circ} 22^{\prime}$ e $25^{\circ} 27^{\prime}$ de latitude sul e os meridianos $49^{\circ} 51^{\prime}$ e $49^{\circ} 56^{\prime}$ de longitude oeste. A altitude varia de 830 a $960 \mathrm{~m}$, apresentando declive suave. O clima local pertence ao tipo Cfb da classificação de Koppen, caracterizado como sub-tropical úmido, com verões frescos, sem estação seca e geadas freqüentes. A precipitação média anual situarse entre 1.400 e $1.500 \mathrm{~mm}$.

A fazenda foi reflorestada com Pinus taeda entre os anos de 1970 e 1973. O espaçamento utilizado foi $2,50 \times 1,60 \mathrm{~m}$, totalizando 2.500 árvores por hectare.

\subsection{Ocorrência do incêndio}

O incêndio florestal analisado ocorreu durante os dias 9,10 e 11 de setembro de 1981, atingindo uma área de aproximadamente 900 ha. A idade dos povoamentos variava de 8 a 10 anos quando ocorreu o incêndio e alguns talhões já haviam sido submetidos ao primeiro desbaste.

As condições climáticas estavam bastante adversas quando ocorreu o incêndio. Durante os três dias de queima a temperatura média situou-se em torna de $22^{\circ} \mathrm{C}$ e a máxima próximo dos $32^{\circ} \mathrm{C}$; a umidade relativa média do ar variou de 25 a $40 \%$ e a velocidade do vento oscilou entre 1 a $6 \mathrm{~m} / \mathrm{s}$. A última precipitação, de $11,9 \mathrm{~mm}$, havia sido registrada 5 dias antes, após longo período de estiagem.

\subsection{Observações de campo}

O trabalho de campo foi realizado com o propósito de caracterizar os niveis de queima e relacioná-los com alguns importantes parâmetros do comportamento do fogo. Observando-se a área queimada foi possível estabelecer quatro níveis de queima:

1) Queima superficial sem crestamento letal das copas;

II) Queima superficial com crestamento letal parcial das copas;

III) Consumo parcial das copas pelas chamas;

IV) Consumo total das copas pelas chamas.

Cada nível de queima no povoamento foi considerado um estrato e por isto se fez uma amostragem estratificada para as medições de campo. Cada amostra tinha $5 \times 16 \mathrm{~m}$, englobando $2 \times 10$ filas de árvores, totalizando $80 \mathrm{~m}^{2}$. As medições foram realizadas em março e abril de 1982, isto é, 6 meses após a ocorrência do incêndio.

\subsubsection{Número de amostras}

O único parâmetro medido diretamente nas parcelas foi a altura das chamas. Por isto, inicialmente se fez uma amostragem preliminar para se obter a variância deste parâmetro em cada estrato.

O número necessário de amostras foi então calculado de acordo com a metodologia de amostragem sequencial, com um limite de erro de $10 \%$ a um nivel de probabilidade de $95 \%$ :

$$
n=\frac{t^{2} \cdot s^{2}}{E^{2}}
$$

sendo:

$$
\begin{aligned}
& n=\text { número de unidades de amostra por es- } \\
& \text { trato; } \\
& s^{2}=\text { variáncia estimada; }
\end{aligned}
$$

\section{0 - Revista floresta}


$\mathbf{t}=$ valor tabelado;

$E=$ erro admissível $(10 \%$ da média preliminar).

\subsubsection{Altura das chamas}

A altura das chamas ficou marcada nas árvores pela carbonização de suas cascas. Esta altura, que variou de acordo com a intensidade de queima, foi medida com uma vara graduada ou com o hipsômetro de Blume-Leiss, onde a vara não alcançava.

A altura das chamas, medida em cada árvore das unidades de amostra, foi posteriormente, através do cálculo das médias, estimada para cada estrato ou nivel de queima.

\subsubsection{Intensidade do fogo}

A intensidade do fogo foi estimada em função da altura média das chamas de cada nível de queima, através da equação de Byram modificada por ROTHERMEL \& DEEMING ${ }^{6}$ :

$$
I=63,05 h_{c}^{2 / 17}
$$

sendo:

$$
\begin{aligned}
& l=\text { intensidade de fogo em } \mathrm{kcal} / \mathrm{m}-\mathrm{s} ; \\
& h_{c}=\text { altura das chamas em metros. }
\end{aligned}
$$

$\mathrm{Na}$ verdade a equação de Byram utiliza o comprimento das chamas. No entanto, devido à dificuldade de medição, a altura pode ser usada como uma boa aproximação do comprimento das chamas.

\subsubsection{Altura de crestamento letal}

Crestamento é a secagem letal da folhagem das árvores, causada pelos gases quentes que se desprendem da zona de combustão. As folhas crestadas não são consumidas pelo fogo, isto é, permanecem intactas porém secas e mortas, com coloração marrom.

A estimativa da altura de crestamento da copa das árvores, parâmetro importante na avaliação dos danos causados pelo fogo, foi feita através da equação desenvolvida por VAN WAGNER ${ }^{9}$ :

$$
h_{s}=\frac{3,941^{7 / 6}}{\left(0,1071+V^{3}\right)^{1 / 2}(60-T)}
$$

sendo:

$h_{s}=$ altura de crestamento letal, em metros;

$\mathrm{I}=$ intensidade do fogo em $\mathrm{kcal} / \mathrm{m}$-s;

$V=$ velocidade do vento em $\mathrm{m} / \mathrm{s}$;

$\mathrm{T}=$ temperatura do $\operatorname{ar} \mathrm{em}^{\circ} \mathrm{C}$.

A velocidade do vento e a temperatura do ar foram obtidos da Estação Meteorológica do Parque Estadual de Vila Velha, situada a $20 \mathrm{~km}$ da área onde ocorreu $o$ incêndio. Os valores médios, correspondentes aos dias em que ocorreu o incêndio, foram $21,9^{\circ} \mathrm{C}$ para a temperatura e $3,22 \mathrm{~m} / \mathrm{s}$ para a velocidade do vento.

\section{RESULTADOS E DISCUSSÃO}

Os números de amostras necessários para atender à precisão desejada, em cada nivel de queima, estão discriminados na Tabela 1.

TABELA 1. NÚMERO DE AMOSTRAS MEDIDAS EM CADA NIVELL DE QUEIMA

\begin{tabular}{cccc} 
Nivel de & $\begin{array}{c}\text {N}^{\circ} \\
\text { Preliminar }\end{array}$ & $\begin{array}{c}\text { No }^{\circ} \\
\text { Necessário }\end{array}$ & $\begin{array}{c}N^{\circ} . \\
\text { Medido }\end{array}$ \\
\hline II & 6 & 5 & 6 \\
III & 6 & 8 & 10 \\
IV & 6 & 7 & 8 \\
\hline
\end{tabular}

Através das alturas médias das chamas foram estimados os demais parâmetros do comportamento do fogo, respectivamente intensidade do fogo $e$ altura de crestamento letal. A análise dos valores desses parâmetros, apresentados na Tabela 2, permite uma boa avaliação dos danos causados pelos diversos níveis de queima às árvores do povoamento. 


\begin{tabular}{|c|c|c|c|c|}
\hline \multirow{2}{*}{$\begin{array}{l}\text { Paràmetros do } \\
\text { Fogo }\end{array}$} & \multicolumn{4}{|c|}{ Niveis de Queima } \\
\hline & 1 & 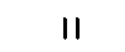 & III & IV \\
\hline Altura de queima $(\mathrm{m})$ & 0,85 & 2,03 & 4,54 & 11,38 \\
\hline Porcentagem de queima em relação à altura da árvore (\%) & 7 & 18 & 40 & 100 \\
\hline Intensidade do fogo $(\mathrm{kcal} / \mathrm{m}-\mathrm{s})$ & 44,3 & 293,0 & 1680,7 & 12345,6 \\
\hline Altura de crestamento $(\mathrm{m})$ & 1,4 & 9,7 & 41,0 & 167,0 \\
\hline Porcentagem de crestamento em relação à altura da árvore (\%) & 12 & 85 & $>100$ & $>100$ \\
\hline
\end{tabular}

Os quatro niveis de queima são também mostrados na Figura 1, onde se observa que no nível IV houve queima total das árvores e no III, queima parcial. Em ambos os casos a altura de crestamento letal ultrapassou a altura total das árvores, matando toda a folhagem das mesmas. Nos nivieis I e II o fogo não chegou a atingir a folhagem das árvores, havendo apenas um crestamento parcial das copas no nível II.

No nivel de queima 1 a altura média das chamas foi de apenas cerca de $7 \%$ da altura total das árvores. A intensidade do fogo foi baixa, cerca de $44 \mathrm{kcal} / \mathrm{m}$-s e a altura de crestamento chegou apenas a $12 \%$ da altura total das árvores, não provocando nenhum crestamento da copa. Conseyüentemente, neste nivel de queima não houve nenhum dano às árvores. Segundo NOSTE \& DAVIS ${ }^{5}$ e SOARES $^{7}$, fogo com esta intensidade, quando aplicado sob forma de queima controlada, pode inclusive ser benéfico ao povoamento sob diversos aspectos.

No nivel II a intensidade média do fogo chegou a $293 \mathrm{kcal} / \mathrm{m} . \mathrm{s}$, excedendo o limite de $132 \mathrm{kcal} / \mathrm{m} . \mathrm{s}$, o qual segundo BROWN \& DAVIS ${ }^{1}$ é o máximo que um povoamento de coníferas pode suportar sem sofrer danos. De fato, nesse nivel de queima as árvores tiveram a copa parcialmente crestada e sofreram pequenos danos devido ao fogo. Entretanto a recuperação das árvores foi muito boa e praticamente não houve mortalidade. As árvores chegaram a apresentar altura de crestamento letal correspondente a $84 \%$ das suas alturas médias. Porém, segundo observado por DIETRICH ${ }^{2}$, as coníferas podem resistir e sobreviver ao crestamento letal de até $90 \%$ da sua altura média total.

No nivel III o fogo chegou a atingir e queimar até uma altura correspondente a $\mathbf{4 0} \%$ da altura média das árvores. A altura de crestamento letal foi inclusive superior à altura das árvores. Conse- qüentemente não restou nenhuma porção viva da copa, ocorrendo mortalidade total das árvores.

No nível IV houve a queima total das árvores, com ocorrência de incêndio de copa e uma intensidade de cerca de $12.345 \mathrm{kcal} / \mathrm{m} . \mathrm{s}$, extremamente alta e com grande poder de destruição. $\mathrm{Ne}$ nhuma árvore consegue sobreviver a esta intensidade de fogo e portanto, nesse nível, a mortalidade foi também total.

A metodologia aqui apresentada para a estimativa dos parâmetros do comportamento do fogo mostrou-se totalmente adequada para determinação dos danos causados pelo fogo a povoamentos de Pinus taeda. Isto é de grande importância para se avaliar os danos provocados pelo fogo a povoamentos desta espécie, imediatamente após a ocorrência dos incêndios.

\section{CONCLUSÕES}

i) A altura média das chamas, obtida através da altura de carbonização das cascas das árvores, foi um bom parâmetro para a estimativa da intensidade do fogo.

ii) A altura de crestamento letal estimada através da intensidade do fogo e $d t$ parâmetros meteorológicos, correspondeu, com precisão, ao observado no campo.

iii) O conhecimento dos parâmetros intensidade do fogo e altura de crestamento letal permitiram avaliar corretamente os danos provocados pelo fogo ao povoamento.

iv) Através dos parâmetros do comportamento do fogo pode-se mapear a área, estabelecendo os tocais onde a floresta tem chance de se recuperar e aqueles onde a mortalidade foi total.

v) A metodologia usada mostrou-se adequada para avaliar os danos provocados pelos incêndios em povoamentos de Pinus taeda na região estudada.

\section{2 - REVISTA FLORESTA}




\section{RESUMO}

Este trabalho foi desenvolvido na Fazenda Rio do Salto, da Slaviero Florestal, situada no município de Palmeira, Estado do Paraná, em um povoamento de Pinus taeda atingido por um incèndio florestal que queimou durante os dias 09,10 e 11 de setembro de 1981. A idade das árvores variava de 8 a 10 anos quando ocorreu o incêndio. Quatro niveis de intensidade de fogo foram identificados visualmente: 1) queima superficial sem crestamento letal das copas; II) queima superficial com crestamento letal parcial das copas; III) consumo parcial das copas pelas chamas e IV) consumo total das copas pelas chamas. Os parâmetros de comportamento do fogo estimados foram altura das chamas, intensidade do fogo e altura de crestamento letal. As intensidades médias de fogo estimadas foram $44,3 \mathrm{kcal} / \mathrm{m}-3$ para o nível $\mathrm{l}$; 293,0 para o 11 ; $1.680,7$ para o III e $12.345,6$ para o IV. As alturas de crestamento médias foram de 1,4 e 9,7 m para os níveis I e $\mid 1$ respectivamente, ultrapassando a altura das árvores nos outros dois níveis de queima. Os níveis de queima III e IV causaram a mortalidade de todas as árvores atingidas pelo fogo; no nível II os danos foram parciais, com boa recuperacão das árvores; no nível de queima I, onde o fogo foi de baixa intensidade, não se observaram danos às árvores.

\section{LITERATURA CITADA}

1. BROWN, A. A. \& DAVIS, K. P. Forest fire: control and use. New York, McGraw-Hill, 1973. 685 p.

2. DIETRICH, J. H. Recovery potential of fire damaged Southwestern ponderose. California, USDA, Forest Service Research, 1979. 8 p.

3. HERMAN, F. R. A guide for marking fire-damage Ponderosa pine in the Southwest. USDA For. Serv. Res. Note RM-13, 1954. 4 p.

4. McARTHUR, A. G. Fire behavior in eucalypt forest. Canberra, Department of Development, Forestry and Timber Bureau, 1967. $36 \mathrm{p}$.

5. NOSTE, N. V. \& DAVIS, J. B. A critical look at fire damage appraisal. Can. J. For., 73(11): 10-15, 1975.

6. ROTHERMEL, R. C. \& DEEMING, J. E. Measuring and interpreting fire behavior for correlation with fire effects. USDA For. Serv. Tech. Report INT93, 1980. 4 p.

7. SOARES, R. V. Provenção e controle dé incêndios florestais. Curitiba, FUPEF, 1982. 72 p.

8. . Queima controlada em plantações de Pinus spp na regiåo de Sacramento, MG. Floresta, 10(2): 33-40, 1979.

9. VAN WAGNER, C. E. Height of crown scorch in forest fire. Can. J. For., $3(3): 373-378,1973$.

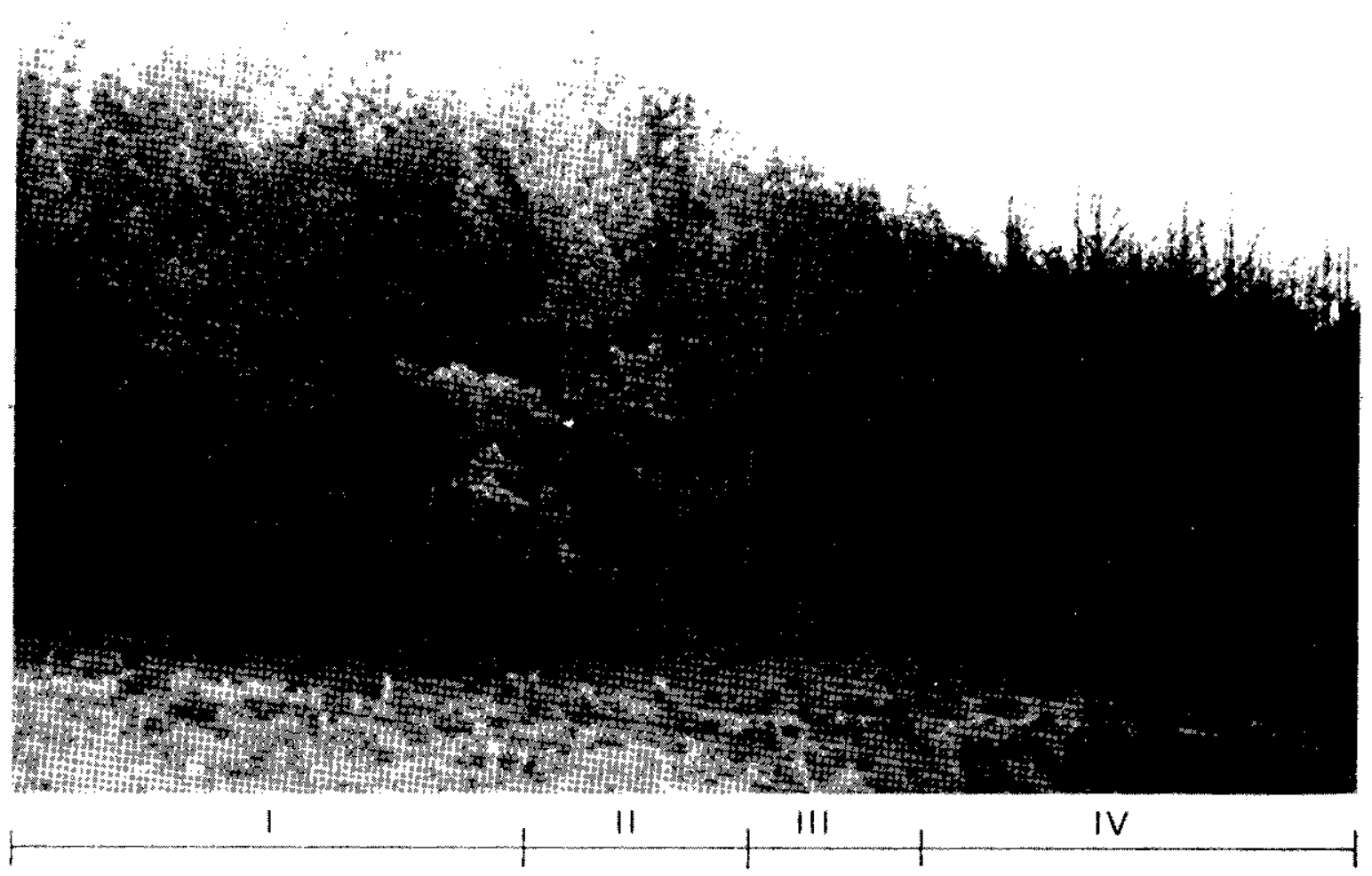

FIGURA 1. Os quatro níve is de queima observados no incêndio. 